\title{
Højden af bjerge \\ - indflydelse af klima i form af glacial erosion
}

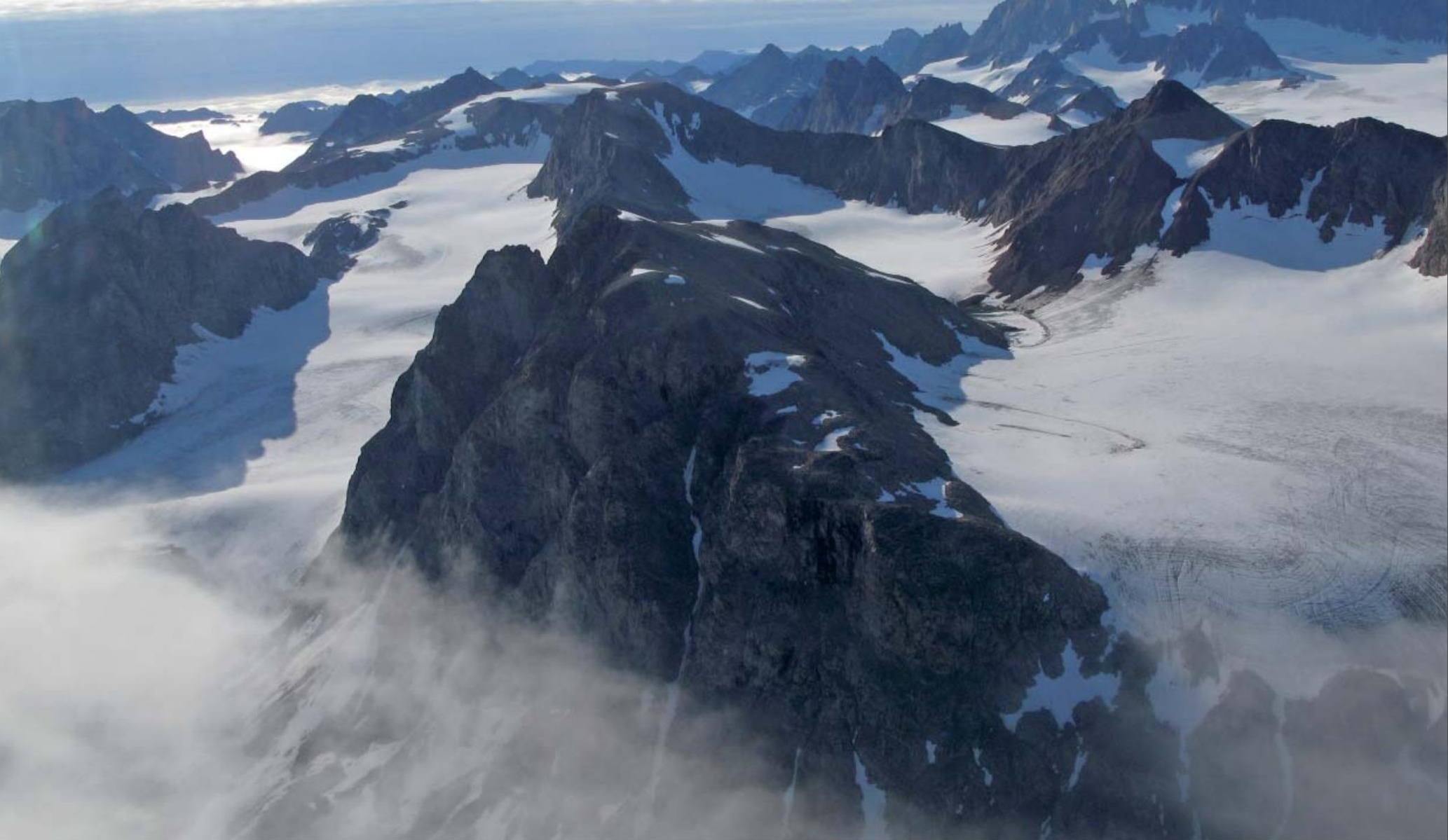

Gletschere er utroligt effektive til at erodere landskabet, og ikke meget areal får lov til at rejse sig over snegrcensen. På billedet ses, hvordan spidse højderygge rejser sig mellem gletscherne i Liverpool Land i Østgrøndand. Hvor isen flyder, vil landskabet udjœvnes, og disse områder vil derfor udgøre en stor andel af landskabets areal. (Foto: Christian Prinds, GEUS, august 2009)

Af Vivi K. Pedersen, David L. Egholm og Søren B. Nielsen, Geologisk Institut, Aarhus Universitet

Hvad bestemmer egentlig, hvor høje bjerge kan blive? Hvorfor ligger Verdens højeste bjerg lige i Himalaya? Kunne det lige så godt ligge et helt andet sted, og kunne det være højere? Noget tyder nu på, at klimaet er den bestemmende faktor for fordelingen af høje tinder her på Jorden.

Selv om vi i Danmark må "nøjes med” Himmelbjerget, har de allerfleste af os oplevet "rigtige bjerge". Bjerge, som vi har set på vandreturen i Norge, på skituren i Alperne eller på et postkort fra en af Verdens andre bjergkæder. Vi fascineres til stadighed af bjergenes majestætiske højde, og mindes om de enorme kræfter, der er på spil på vores planet.

\section{Højden af bjerge}

Højden af en bjergkæde afspejler et sammenspil mellem tektonisk hævning (fx forårsaget af kollision mellem kontinenter), skorpens styrke og nedbrydningen af topografi ved overfladen, men hvordan de forskellige mekanismer arbejder sammen, er stadig et varmt emne inden for geovidenskaberne.

Hidtil har man troet, at højden af bjerge primært bestemmes af den intensitet, hvormed kontinentale plader kolliderer og herved bygger bjergene op samt jorskorpens styrke, men nu tyder noget på, at erosionsprocessernes effekt ved overfladen er af større betydning end før antaget.

Gletschere har altid haft ry for at være meget effektive til at erodere, mens det først den seneste tid er blevet klart, at de også spiller en stor rolle, når vi skal besvare spørgsmålene om bjerges højde.

Montgomery et al. (2001) observerede i Andesbjergene, at topografien langs bjergkæden korrelerede med den lokale snegrænse. Dette resultat er nu blevet ud- bygget til hele kloden i studiet fremlagt af Egholm et al. (2009). De nye resultater byg- 


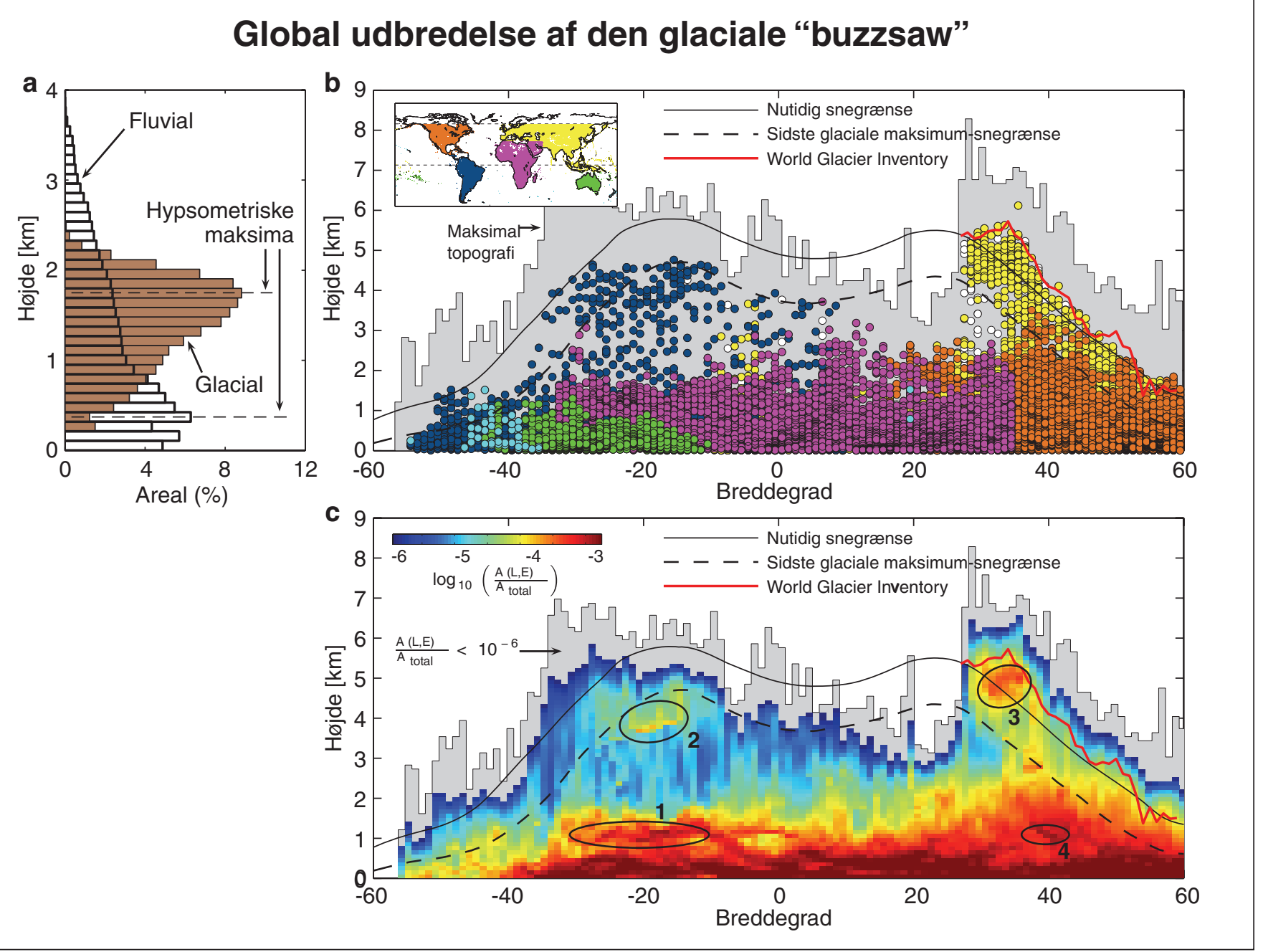

a: Hypsometrisk fordeling fra et fluvialt (nordlige Andes) og et glacialt (Cascade Range, USA) landskab. Begge hypsometrier har et lokalt maksimum, men ved forskellig højde. Den hypsometriske fordeling reprcesenterer hver $1^{\circ} \times 1^{\circ} \mathrm{DEM}$ med koordinaterne (nedre venstre hjørne) $\left(09^{\circ} \mathrm{N}, 71^{\circ} \mathrm{W}\right)$ for den fluviale og $\left(48^{\circ} \mathrm{N}, 121^{\circ} \mathrm{W}\right)$ for det glaciale. $\boldsymbol{b}$ : Den globale fordeling af hypsometriske maksima som funktion af breddegrad og højde. Hvert hypsometriske maksimum er reprcesenteret af en cirkel, hvor farven angiver placeringen (øvre venstre hjørne). Hypsometriske maksima fra DEM'er med mere end $5 \%$ datahuller er hvide. Det grå område viser den totale datadcekning og angiver derfor den maksimale højde for hver breddegrad. Yderligere ses den moderne snegrcense (sort streg) og snegrcensen for sidste glaciale maksimum (sort stiplet linje) langs Amerikas vestkyst samt en snegrcense (rød linje), der reprcesenterer mere end 13.000 snegrcense-observationer fra World Glacier Inventory databasen (midlet for hver breddegrad). c: Fordelingen af overfladeareal (A) i forhold til breddegrad (L) og Højde (E). Farverne indikerer mengden af areal for en given breddegrad og højde normeret til det totale areal $\left(A_{\text {tota }}\right)$. Farveskalaen er logaritmisk. Det grå område udgør kun et meget lille areal og falder derfor uden for farveskalaen (men viser den maksimale topografi). Ellipserne markerer tektonisk opløftede plateauer: 1, Sydafrika; 2, Altiplano; 3, det tibetanske plateau; 4, Tarim Bassinet. (Grafik: Fra Egholm et al. (2009))

ger på en næsten global landskabsanalyse lavet på baggrund af digitale højdemodeller (DEM'er: digitale elevationsmodeller), samt numeriske simuleringer af glacial erosion. Det samlede resultat viser, at glacial erosion i form af den lokale snegrænse (nedre grænse for hvor sne og is kan akkumulere) afgør, hvor høje bjerge kan blive. Da snegrænsens højde afhænger af klimaet, vil bjerges højde afspejle den klimatiske gradient, man finder på Jorden fra polerne mod ækvator.

\section{Hvor findes Jordens høje bjerge?}

En global analyse af Jordens overflade viser $\mathrm{nu}$, at fordelingen af topografi og Jordens høje bjergtinder, langt fra er tilfældigt placeret.

Analysen viser en slående sammenhæng mellem fordelingen af topografi på
Jorden og snegrænsens variation fra pol til pol, således at mængden af overfladeareal falder drastisk over den lokale snegrænse. Størstedelen af Jordens topografi er tæt på havniveau, og mængden af overfladeareal falder generelt med højden. Ved snegrænsen reduceres overfladearealet dog pludseligt, og kun stejle bjergtinder rejser sig over dette niveau. På høje breddegrader, hvor temperaturen er lav, vil snegrænsen findes tæt på havniveau, og den observerede topografi ses at korrelere med dette relativt lave niveau. Når man nærmer sig ækvator, vil snegrænsen på grund af den højere temperatur i atmosfæren stige og give plads til højere bjergtinder. Da akkumuleringen af sne og is kræver både lave temperaturer og nedbør, er snegrænsen højest omkring $30^{\circ} \mathrm{N} / \mathrm{S}$ ved de to højtryksceller (ørkenbælterne).
Dette mønster ses da også at korrelere med placeringen af både Himalaya og den høje centrale del af Andesbjergene, hvor mange af Verdens højeste tinder findes.

Analysen er lavet på Shuttle Radar Topography Mission data indsamlet af NASA om bord på Endeavour rumfærgen i 2000 og dækker alt landareal mellem $60 \mathrm{~N}$ og $60 \mathrm{~S}$. (Se faktaboks for yderligere informationer). I områder, der er høje nok til at være under indflydelse af snegrænsen (nu eller under sidste glaciale maksimum), giver en analyse af områdets fordeling af overfladeareal med højde - hypsometrien - et karakteristisk udtryk. Lige under den lokale snegrænse vil der være en relativt stor koncentration af overfladeareal, mens koncentrationen af overfladeareal er kraftigt faldende over den lokale snegrænse. 


\section{Computersimuleringer}

\section{Numerisk model af glacial erosion i Sierra Nevada}
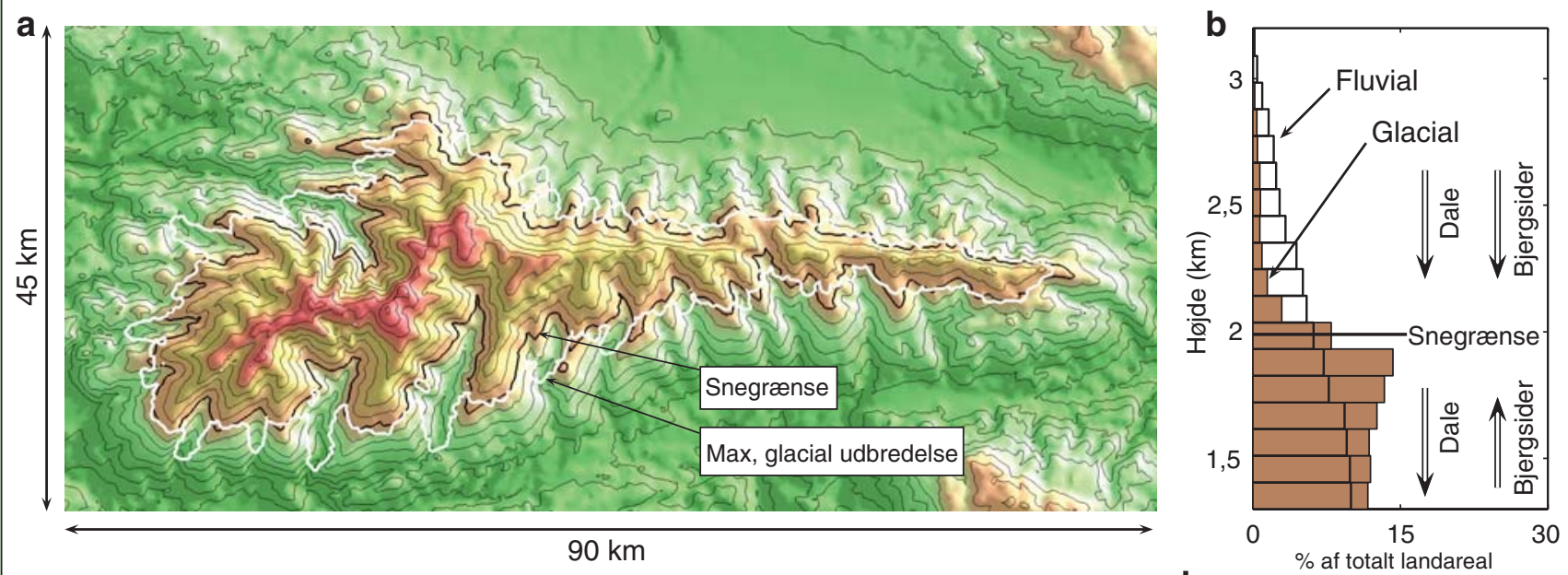

C

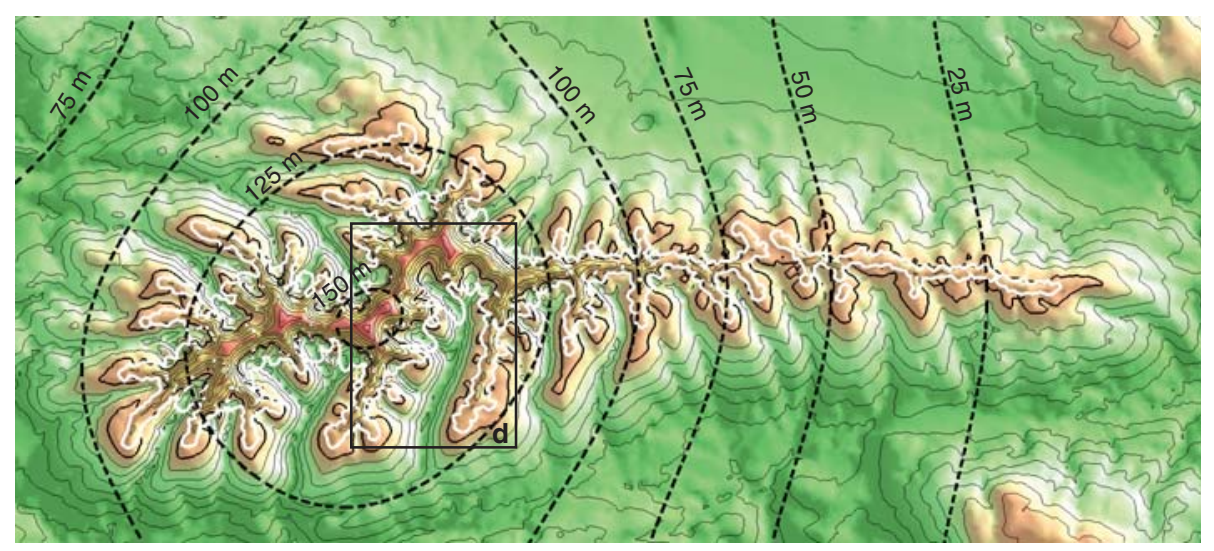

d

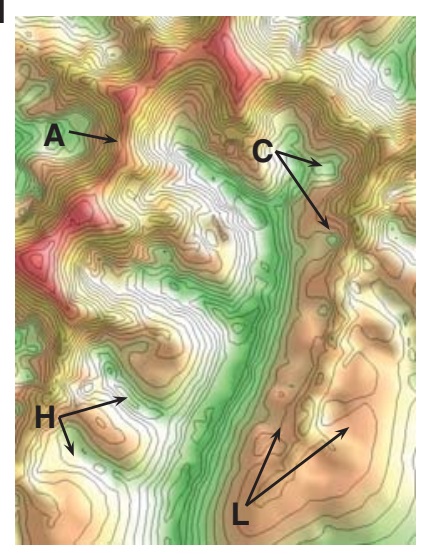

Numerisk model af glacial erosion i Sierra Nevada (Spanien). a: Det initiale fluviale landskab udledt af SRTM-data (se faktaboks). Under simuleringen sæenkes snegræensen med $1000 \mathrm{~m}$ til $2000 \mathrm{~m}$ (fed sort streg). Den hvide streg angiver den maksimale udbredelse af gletschere under modelleringen. $\boldsymbol{b}$ : Hypsometrisk fordeling før og efter glacial erosion. Der udvikles et hypsometrisk maksimum lige under snegrcensen. Dette skylder erosion i små dale og på bjergsider over snegrænsen samt isostatisk opløft af bjergsider under snegrœnsen, hvor der kun har vœret begrænset erosion. c: Model-topografi efter glacial erosion. Over snegrænsen findes kun smalle, stejle højderygge. Under snegrcensen er dale blevet dybere og bredere. Mcengden af isostatisk opløft ses med sorte stiplede konturlinjer. d: Forstørrelse at et område, hvor der ses stejle højderygge (arêtes - A), cirkusdale (C), høengende dale (H) og lav-relief områder (L). (Grafik: Fra Egholm et al. (2009))

For at simulere dannelsen af glaciale landskaber skal man først have styr på, hvordan isen opfører sig. Her løses et sæt ligninger, der beskriver, hvordan is akkumuleres og bevæger sig, når tykkelsen bliver stor nok i forhold til landskabets hældning og isens temperatur. Hvis isen flyder under snegrænsen, begynder afsmeltningen. I områder, hvor isen er meget tyk eller flyder meget hurtigt, vil den kunne nå væsentligt ned under snegrænsen, hvilket kan resultere i store brede og dybe U-formede dale.

Isbevægelsen kobles med en beskri- velse af erosion, som en konsekvens af at gletscheren skrider hen over underlaget og herved fjerner materiale fra underlaget. Som følge af erosionen vil landskabet aflastes og hæves (isostasi). På grund af lithosfærens styrke vil hævningen omfatte hele bjergområdet, inklusiv de spidse tinder og lavtliggende bjergskråninger, der ellers kun oplever begrænset erosion, og disse vil faktisk løftes til en lidt højere position, end før erosionen begyndte (overordnet vil erosionen selvfølgelig sænke landets gennemsnitshøjde).

Som et eksempel, der skal illustrere konsekvenserne af glacial erosion i et landskab, er den lille bjergkæde Sierra Nevada i det sydlige Spanien valgt. Denne bjergkæde har kun været udsat for minimal påvirkning af glacial aktivitet i Kvartæret, og dette har resulteret i et gennemgående fluvialt landskab. Ved at simulere en sænkning af temperaturen indføres der is og herved glacial erosion, og således kan landskabet, der er et resultat af glacial erosion, undersøges. (Flere eksempler ses i Egholm \& Piotrowski (2007)).
I alpine landskaber genkendes denne karakteristiske fordeling af overfladeareal versus højde, ved at bjergtoppene består af spidse horn og knivskarpe bjergrygge, mens der længere nede i landskabet findes store områder med relativt lavt relief, hvor der ofte er eller har været is, og hvor fryse-tøprocesser udjævner landskabets konturer.
Den maksimale topografi (tinder og bjergrygge) ses også at korrelere med snegrænsen, og det tyder på, at det maksimale relief, der kan opbygges over den lokale 


\section{Shuttle Radar Topography Mission}

I februar 2000 blev rumfærgen Endeavour sendt på en 11 dage lang mission. Missionen var et samarbejde mellem NASA (den amerikanske rumfartsadministration) og de tyske og italienske rumfartsinstitutioner, og målet var at lave et "nær-globalt” datasæt af Jordens overflade med en meget høj opløselighed.

Ved hjælp af radar-interferometri opmålte man fra $233 \mathrm{~km}$ over Jordens overflade en digital repræsentation af Jordens topografi. Rumfærgen fløj i alt 159 gange rundt om Jorden og opmålte derved alt landareal minimum én gang.

Resultatet var en digital højdemodel (digital elevationsmodel - DEM) for alt landareal mellem $60^{\circ} \mathrm{N}$ og $60^{\circ} \mathrm{S}$. Denne store mængde data har en opløselighed på 3 sek. svarende til 90 m ved ækvator. Man har altså en højdemåling for mini- mum hver 90 m overalt på Jordens overflade mellem $60^{\circ} \mathrm{N}$ og $60^{\circ} \mathrm{S}$.

Det enorme datasæt er frit tilgængeligt på internettet:

(http://dds.cr.usgs.gov/srtm/). Her ligger 14.546 DEM-filer, der hver repræsenterer $1^{\circ} \times 1^{\circ}$ af Jordens overfladeareal, svarer cirka til $100 \times 100 \mathrm{~km}$.

Se mere om missionen på:

http://www2.jpl.nasa.gov/srtm/

Illustration af måleproceduren. Radarsignal udsendes fra antenne monteret på rumfcergen (rød linje). Det reflekterede signal modtages både af antennen på rumfcergen og af en antenne monteret på en mast $60 \mathrm{~m}$ ud fra rumfergen. Tilsammen giver de to målinger mulighed for nøjagtigt at beregne højden af topografien (ht). Højden over referenceniveau er

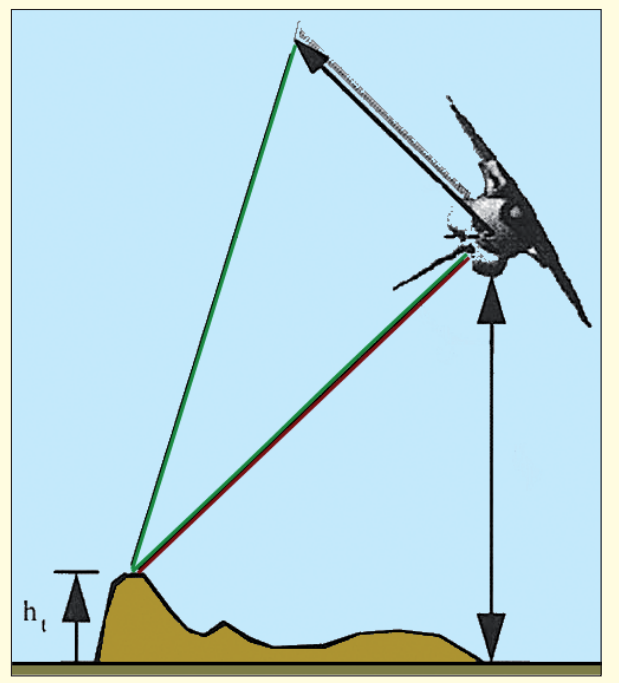

konstant (233 km over havniveau).

(C) www2.jpl.nasa.gov/srtm/multimed.htm)

Illustration af En-

deavour rumfergen under Shuttle Radar Topography Mission'en. En antenne er placeret på rumfergen, en anden er monteret på en $60 \mathrm{~m}$ lang mast. (C) www2.jpl.nasa. gov/srtm/multimed. $h t m)$

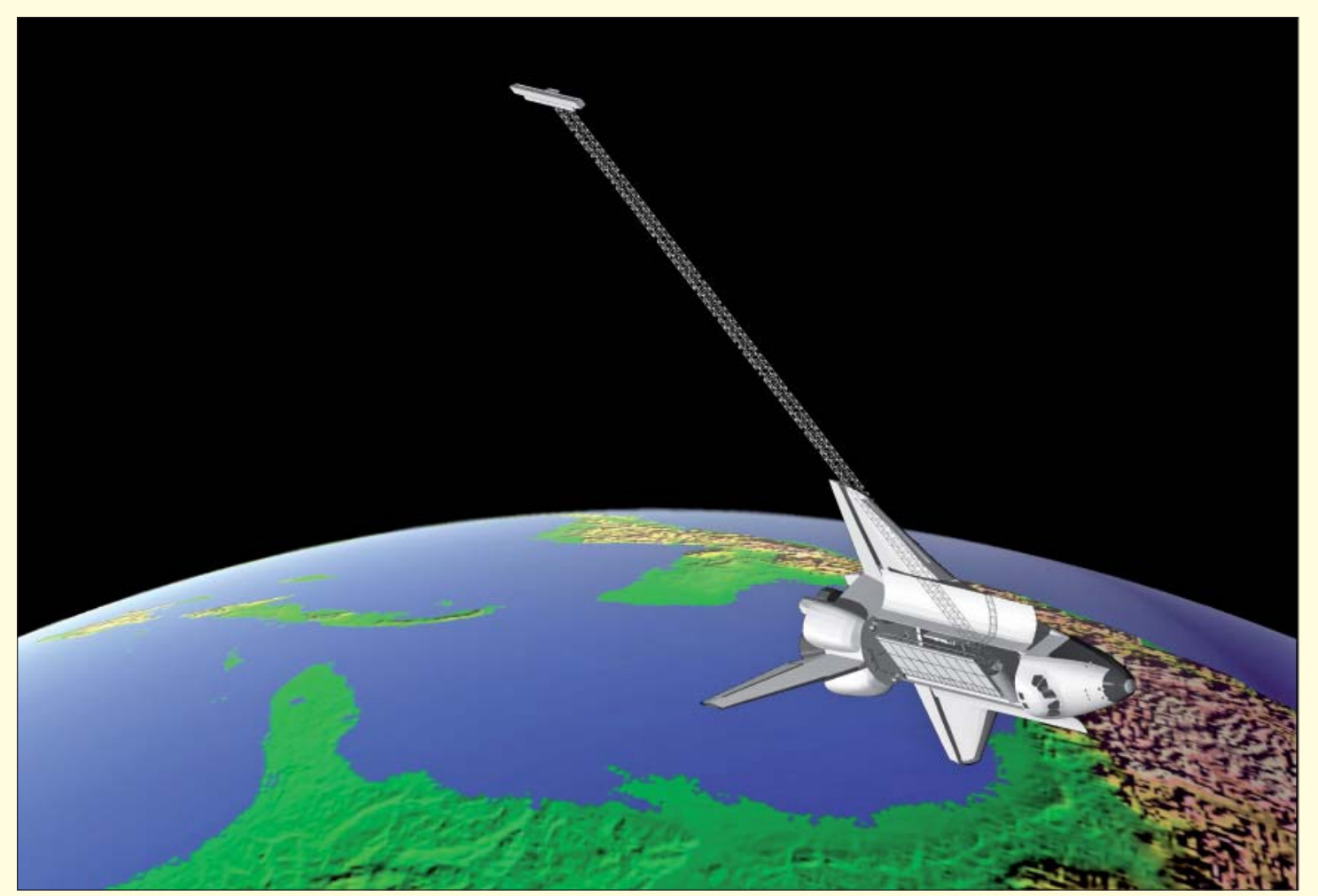

snegrænse, generelt ikke overstiger 1.500 $\mathrm{m}$. Gletscherne over snegrænsen vil effektivt erodere landskabet og kun efterlade en meget stejl topografi, der på et tidspunkt styrter sammen, fordi der er grænser for, hvor længe meget stejle tinder kan blive stående.

De alpine processers evne til at begrænse bjerges højde går under navnet "den glaciale rundsav" (the glacial buzzsaw), da det ofte ser ud, som om en sav har været på spil og har skåret toppene af bjergene i samme højde.

\section{Numerisk simulering}

Mekanismerne bag de globale observationer kan undersøges vha. numerisk modellering, hvor isbevægelse kobles med glacial erosion, (som opstår når tempererede gletschere skrider hen over underlaget) og flexurel isostasi. (se boks for flere detaljer).

Den nye numeriske modellering af glacial erosion, der præsenteres i Egholm et al. (2009) er i stand til at simulere dannelsen af kendte glaciale landskabsfænomener som U-formede dale, hængende dale, overdyb- ninger, arêtes (bjergrygge) og cirkusdale. Dette er nyt inden for modelleringen af isbevægelse og glacial erosion, men også et nødvendigt kvalitetskrav for en numerisk model. Ud over de klassiske glaciale landformer forudser de numeriske eksperimenter også dannelsen af lav-relief-landskaber lige under snegrænsen, svarende til dannelsen af et maksimum i den hypsometriske fordeling i denne højde, og bekræfter således den tidligere fremsatte hypotese om landskaberne i det vestlige Skandinavien (Nielsen, 2007). 
I modellen forklares dannelsen af de relativt flade landområder lige under snegrænsen med en kombination af glacial erosion og isostatisk hævning. Over snegrænsen vil glacial erosion være effektiv både i dale og på bjergsider, mens den under snegrænsen er begrænset til dale. Den isostatiske hævning omfatter alle områder i bjergkæden også bjergskråninger under snegrænsen, hvor der kun sker lidt erosion, og som derfor netto vil opleve hævning. Glacial erosion over snegrænsen vil altså forsøge at bringe landoverfladen/landareal ned mod snegrænsen, mens isostatisk hævning af bjergsiderne under snegrænsen vil forsøge at bringe overfladeareal mod snegrænsen nedefra. Resultatet er et lokalt maksimum i den hypsometriske fordeling, som er sammenligneligt med hvad der observeres i den globale landskabsanalyse.

De globale observationer kan altså ud fra de numeriske simuleringer forklares ud fra sammenspillet mellem glacial erosion og isostatisk hævning.

\section{Undtagelserne der bekræfter regelen}

Der findes undtagelser, der afviger fra den generelle trend, der er observeret i den globale landskabsanalyse. Et eksempel er de Transantarktiske bjerge, der med en maksimal højde på mere end $4.500 \mathrm{~m}$ rejser sig langt over den lokale snegrænse ved havniveau, og derved skiller sig fuldstændig ud fra andre bjergkæder. Andre forskere har foreslået, at dette skyldes, at gletscherne på Antarktis er bundfrosne, hvilket reducerer den glaciale erosion voldsomt (Stern, 2005).

En anden vigtig undtagelse er vulkaner, som kan vokse meget hurtigere, end gletschere kan erodere. Eksempler på dette findes blandt andet i Andesbjergene og i Alaska. Undtagelserne er ofte meget berømte (fx Mount Everest og Mount McKinley), men der er også ganske få af dem i forhold til antallet af bjerge på Jordens overflade - hvilket formentlig er med til at gøre dem så berømte.

\section{Summa summarum}

Der er altså tale om en øvre grænse for dannelsen af topografi, og denne øvre grænse er knyttet til snegrænsens højde. Pladetektonik udgør stadig den drivende kraft, når der skal bygges bjerge, men det tyder på, at klimaet i form af glacial erosion bestemmer den øvre grænse for, hvor høje bjerge kan blive, uafhængigt af mængden af tektonisk hævning.

\section{Referencer:}

Montgomery, D. R., G. Balco, and S. D. Willett (2001). Climate, tectonics, and the morphology of the Andes. Geology 29 (7).

Egholm, D. L., S. B. Nielsen, V. K. Pedersen \& J.-E. Lesemann (2009). Nature 460, 884887.

Stern, T. A., A. K. Baxter, P. J. Barrett (2005). Isostatic rebound due to glacial erosion within the Transantarctic Mountains. Geology, 2005, 33, 3, 221-224.

Nielsen, S. B. (2007). Norges fjelde - og den naturvidenskabelige proces. GeologiskNyt, 3/07, 22-24

Egholm, D. L. \& J. A. Piotrowski (2007). Er gletschere uberegnelige? - nyt tvcerfagligt modelleringsprojekt. GeologiskNyt, 3/07, 16-20.

\section{Lomborgs model}

For 45 mia. kr. kan den globale opvarmning standses. Det kunne man læse på forsiden af Jyllands-Posten 7. august. Bjørn Lomborg, der er leder af Copenhagen Consensus ved Copenhagen Business School, der har fået 5 mio. kr. af den danske stat til at skaffe oplysninger og information om omkostninger og fordele ved forskellige klimatiltag, har regnet på, hvad der vil koste at sende en armada af 1.900 førerløse skibe ud på verdenshavene for at skabe skyer ved at oppiske saltvand og sende vandpartikerne op i luften.

Idéen, der er fostret af den skotske professor Stephen Salter, går ud på, at eftersom luften over havet ofte indeholder for få af de særlige partikler, der får luften til at kondensere og skabe skyer, må mennesket træde til og hjælpe. Via skykanoner på førerløse skibe sprayes havvand op i luften, hvorved mængden af skydannende partikler fordobles, hvilket skaber skyer, der som bekendt nedsætter solens opvarmende effekt på Jor- den. De selvsejlende skibe skal ifølge den skotske professor drives ved hjælp af vind som energikilde.

Bjørn Lomborg mener, at en sådan investering vil kunne give pengene igen 2.000 gange. Ifølge Bjørn Lomborg skal man hellere fokusere på sådanne løsningsmodeller end at bruge alle kræfter og penge på at nedbringe udledningen af $\mathrm{CO}_{2}$ og drivhusgasser i atmosfæren, der på indeværende tidspunkt er både for dyre og har for lille effekt.

Bjørn Lomborg har gjort sig til talsmand for at implementere de miljømæssige tiltag, hvor politisk ukorrekte de end måtte være, der kan give de største klimaforbedringer for de til rådighed stående midler.

Selv om der ikke er enighed iblandt klimaforskere om det hensigtsmæssige i at manipulere klimaet, viser adskillige forskningsprojekter fra blandt andet klimaøkonomer, at der kan opnås betydelige gevinster ved at manipulere klimaet.

$J P / S L J$ 